\title{
Weights, Measures, and Exchange Rates
}

dan A measure of weight equal to between roo and I 50 jin, with local variation; or, a measure of volume for grain approximately equal to 2.75 bushels, also pronounced shi. In the Character List, only the first character for "dan" can also be pronounced "shi"; this character is always used for specifying grain by volume. The second character with the pronunciation "dan" is used for measuring the weight of other items, such as cocoons. In Wuxi, one dan of rice (before milling) weighed between 135 and 150 jin.

fen One fen equals I/ Io mao.

jin (or catty) A measure of weight equal to between I.I and I.3 pounds, with local variation.

li A measure of distance approximately equal to 0.33 mile or 0.20 kilometer.

mao One mao equals I/Io yuan.

$\mathrm{mu}$ A measure of area approximately equal to 0.67 acre.

picul A measure of weight equal to I, 000 dan, or between Ioo and I 50

pounds. The national standardized weight of I picul was I 33.33 pounds in the early twentieth century.

tael The Chinese ounce, a measure of weight equal to one-sixteenth of a jin; also a unit of account (with varying values) for uncoined silver money. In I92 I, I tael equaled US\$0.76.

yuan (¥) The Chinese dollar, the most common unit of account during the early twentieth century. In I92 I, one yuan equaled US\$1.04.

SOURCES: Rawski and Li 1992: xiii; Webster's Third New International Dictionary I96I; A Chinese-English Dictionary (Beijing: Shangwu yinshuguan, I978); Chinese Economic Monthly 5 (Feb. I924): I I. 

ONE INDUSTRY, TWO CHINAS 
